Research articles

\title{
Using the 'dispersion-retention-formulation method' to estimate clinical and preclinical dosage limits for interstitial nanomedicines or agents
}

\author{
Paul Southern ${ }^{\mathrm{a}, \mathrm{b}}$, Quentin A. Pankhurst ${ }^{\mathrm{a}, \mathrm{b}}$ \\ ${ }^{a}$ Resonant Circuits Limited, 21 Albemarle Street, London W1S 4BS, UK \\ ${ }^{\mathrm{b}}$ Healthcare Biomagnetics Laboratory, University College London, 21 Albemarle Street, London W1S 4BS, UK
}

\section{A R T I C L E I N F O}

\section{Keywords:}

Nanomedicines

Magnetic fluids

Magnetic nanoparticles

Interstitial administration

\begin{abstract}
A B S T R A C T
We propose the "DRF method" for estimating dosage limits for interstitially administered therapeutic or diagnostic nanomedicines or agents from three characteristic parameters that can be experimentally determined from in vivo data. These are: (i) the dispersion of the injected fluid around the injection site; (ii) the retention of the injected fluid at the injection site; and (iii) the formulation characteristics of the fluid with respect to local and systemic tolerability. We present formulae that allow dose-limit estimates to be made for any preclinical model, as well as for clinical studies. We illustrate the DRF method for the case of iron-oxide-based magnetic fluids, with reference to the published dose limits of regulatory-body-approved magnetic nanoparticles for MRI contrast enhancement, sentinel node detection, iron replacement therapy, and magnetic thermoablation.
\end{abstract}

\section{Introduction}

Given the widespread and increasing interest in nanomedicines for healthcare applications in man [1-4], there are a growing number of academic and commercial research teams around the world that are grappling with the challenges of preclinical-to-clinical translational research. One of the most onerous of these challenges is the question of 'dose versus response', i.e. estimating how much of a given agent one may administer to a patient in order to elicit a desired therapeutic or diagnostic benefit.

In one sense the answer to this question is simple: one needs to run a dose-escalation clinical study to determine, in man, the dose-response characteristics. However, to undertake such a study one needs first to successfully negotiate numerous preparatory studies, generally including preclinical dose-escalation safety and efficacy studies, and firstin-man safety studies at non-therapeutic dosage levels.

But before even embarking on these preparatory studies, it is important to have an understanding of the preclinical-to-clinical pathway, especially with regard to the clinical feasibility of the target agent. Without such a perspective, there is a significant risk that costly, timeconsuming, and potentially unethical preclinical studies may be performed on substances that may have almost no chance of ever being accepted for clinical use. A particular risk here is the situation where a new agent is tested in a preclinical model at dose levels that are sufficient to elicit the desired response in the animal, but which, if translated to the equivalent dose in humans, would exceed the acceptable dosage limits for that substance in man.

Well-established procedures and guidelines are available to help researchers and developers to design appropriate preclinical models, and to gather the requisite information to progress along the translational path. One of the most important of these is the US Food and Drug Administration's 'guidance for industry' report on how to estimate the maximum safe starting dose for first-in-man safety studies in healthy adult volunteers [5]. This report contains invaluable information on, and guidelines for, the preclinical and clinical testing of therapeutic agents, and covers both intravenous (injection into the bloodstream) and interstitial (injection into tissue) administration routes.

However, it is evident from the academic literature that, apart from some notable exceptions - e.g. the review by Dawidczyk et al. [6] - the awareness of, and adherence to, such regulation-based preclinical-toclinical procedures is currently confined almost exclusively to commercial laboratories.

To promote better translational research and better engagement between industry and academia in the field of nanomedicine, we believe that it would be beneficial if more academic research teams were to be aware of, and adhere to, more regulation-based procedures. For this reason, we have recently published a commentary article on the matter [7], focusing on the preclinical and clinical dosage limits of ironoxide-based magnetic fluids.

In this contribution, we present a more formula-based approach to the problem, which is intended to be applicable to any interstitially administered nanomedicine or agent, irrespective of its mechanism of

E-mail address: q.pankhurst@ucl.ac.uk (Q.A. Pankhurst). 
action. We refer to this as the "dispersion-retention-formulation (DRF) method", and intend that it should be easily adopted in academic settings, most especially in the context of preclinical study design. We describe the parameters involved, and the type of preclinical dose-escalation experiments that should be performed to determine them. Lastly, we illustrate the method for the case of iron-oxide-based magnetic fluids.

\section{Nanomedicine or agent dosage limits}

\subsection{Underlying principles and definitions}

To adopt the terminology of regulatory agencies such as the US Food and Drug Administration (FDA), our objective is to estimate the 'maximum recommended starting dose' (MRSD) for the initial clinical studies of a given therapeutic or diagnostic agent. This starting dose is generally determined to be one-tenth of the 'human equivalent dose' $(H E D)$ of the preclinically-determined 'no observed adverse effect level' (NOAEL) of the agent [5]:

$M R S D=\frac{H E D \text { of the animal NOAEL }}{10}$

The 'adverse effects' referred to here are not proscriptively specified, and will vary from agent to agent, but the FDA does suggest some suitable indicators, viz.: overt toxicity (e.g. clinical signs, macro- and microscopic lesions); surrogate markers (e.g. serum liver enzyme levels); and exaggerated pharmacodynamic effects [5].

The way in which one determines the HED from a measured NOAEL is dependent on the administration route of the agent. For intravenous (i.v.) injection both metrics are measured per unit mass, in $\mathrm{mg} / \mathrm{kg}$ (i.e. milligrams of active ingredient per kilogram mass of the animal or human subject); and scaling factors $K_{\mathrm{m}}$ are applied:

$H E D_{\text {i.v. }}=\frac{N O A E L_{\text {i.v. }}^{\text {animal }} \times K_{\mathrm{m}}^{\text {animal }}}{K_{\mathrm{m}}^{\text {human }}}$

The principle behind the use of the $K_{\mathrm{m}}$ scaling factors is to normalise for the body surface area, which is taken to correlate with species-specific metabolic rates (see Table 1). They are estimated by dividing the average body weight of the species by its corresponding average body surface area.

The FDA notes three categories of agent for which the body-surfacearea scaling is not recommended [5]. These are: (1) those administered by non-intravenous routes for which the dose is limited by local toxicities, which should be normalised to concentration or amount at the application site; (2) those administered into anatomical compartments that have little subsequent distribution outside of the compartment, which should be normalised to the species-dependent compartment volume and agent concentration; and (3) intravenously administered high-molecular-weight (more than $100 \mathrm{kDa}$ ) proteins, which should be normalised to body weight.

In this paper we focus on interstitial administrations of the type that

Table 1

Selected body-surface-area scaling factors, $K_{\mathrm{m}}$, as used in equation (2) to convert measured intravenous NOAELs in animals to corresponding HEDs [5]. The 'Ratio' column shows the resultant scaling factor $K_{\mathrm{m}}{ }^{\text {species }} / K_{\mathrm{m}}$ human (adult). (* Note that the scaling factor in children is less than in adults, which should be taken into account if the agent is intended for paediatric use.)

\begin{tabular}{lll}
\hline Species & $K_{\mathrm{m}}\left(\mathrm{kg} / \mathrm{m}^{2}\right)$ & Ratio \\
\hline Mouse & 3 & 0.081 \\
Rat & 6 & 0.162 \\
Rabbit & 12 & 0.324 \\
Human (child)* & 25 & 0.675 \\
Mini-pig & 35 & 0.946 \\
Human (adult) & 37 & 1 \\
\hline
\end{tabular}

are most commonly used for nanomedicines - i.e. direct injection of particulate agents in fluid suspensions into non-compartmental tissues for which it is most convenient to normalise to the concentration (rather than mass) of the agent at the injection site. In such cases the HED and NOAEL metrics are both measured per unit volume, in $\mathrm{mg} / \mathrm{ml}$ (i.e. milligrams of active ingredient per millilitres volume of the target tissue in the animal or human subject), and no inter-species scaling factors are applied [5]:

$H E D_{\text {interstitial }}=N O A E L_{\text {interstitial }}^{\text {animal }}$

This is entirely different from the case for intravenous administration, and reflects the point that this is a local, rather than a systemic, route.

It is notable that Eq. (3) is based on the local concentration of the agent in the tissue, and that as such the dispersion characteristics of the agent - the ratio $V_{\mathrm{d}} / V_{\mathrm{i}}$ where $V_{\mathrm{d}}$ is the tissue volume throughout which an injected volume $V_{i}$ of an agent spreads - are critical. A corollary of this is that the physical characteristics of the tissue itself is important, and that care must be taken to ensure that the animal model is suitable for the intended administration route of the agent - e.g. whether it is intradermal, subcutaneous, intramuscular, intraperitoneal, or intratumoural.

Another key factor associated with interstitial injections into noncompartmental tissues is the question of retention, i.e. the degree to which the agent stays in the target tissue, as opposed to diffusing away through the extracellular medium, or otherwise finds its way into the vascular system. (The latter includes mechanisms such as 'involuntary extravasation', or accidental injection into a blood vessel.) This is important as it implies that unless one can be $100 \%$ certain that all of the injected material will stay in the tissue and not migrate away, then it will be necessary to undertake both local and systemic NOAEL tests in the preclinical studies.

A third and related factor is the formulation of the agent, primarily in terms of its local and systemic tolerability, but also in terms of its biodistribution characteristics. This can be a difficult matter of balancing competing factors, for example in cases where excipients may be added to the agent that make it more likely to be retained at an interstitial injection site, but then make it less tolerable in the event that it does find its way into the bloodstream.

For any given agent, there may be several other factors that affect the estimation of the MRSD for the first-in-man studies, that should be considered on a case-by-case basis. For example, one should be aware of the local guidelines (for the intended clinical study site) governing the allowable injection volumes of any investigational agent, in a given organ, or intravenously. Equally, corresponding limits on injection volumes may be in place for preclinical study animal facilities, which should be considered in the design of the translational research project.

That said, in our opinion the three generic factors of dispersion, retention, and formulation are common to most particulate agents, and as such we consider it valuable to develop the DRF method to help codify their treatment.

\subsection{DRF method for dosage estimation}

For intravenous agents, the design of preclinical dose-escalation studies to estimate $N O A E L_{\text {i.v. }}(\mathrm{mg} / \mathrm{kg})$ values, and the transfer of those values to an estimated $M R S D_{\text {i.v. }}(\mathrm{mg} / \mathrm{kg}$ ) for the initial clinical studies, is relatively straightforward, and is described by Eqs. (1) and (2).

For non-compartmental interstitial agents, the situation is more complicated. Here, unless there is demonstrably a zero chance of transfer of the injected agent into the blood stream, it is necessary to undertake two sets of preclinical dose-escalation studies, one to estimate $N O A E L_{\text {i.v. }}(\mathrm{mg} / \mathrm{kg})$, and one to estimate $N O A E L_{\text {interstitial }}(\mathrm{mg} / \mathrm{ml})$. In addition, following interstitial injection, histopathology or other appropriate methods should be undertaken to determine the 'dispersion factor': 
$v=\frac{V_{\mathrm{d}}}{V_{\mathrm{i}}}=\frac{\text { Tissue volume the agent spreads into }}{\text { Injected volume of the agent }}$

and biodistribution studies should be undertaken to determine the 'retention factor':

$\mathscr{R}=\frac{\text { Amount of agent retained at the injection site }}{\text { Total amount injected }}$

where the 'amount' here refers to some measurable indicator of the agent's active ingredients, such as a fluorescent or radioactive label.

This then leads to a modified version of Eq. (3) for non-compartmental interstitial agents:

$$
\begin{aligned}
& H E D_{\text {interstitial }}^{\text {DRF systemic }}=(1-\mathscr{R}) \times H E D_{\text {i.v. }} \text {; and } \\
& H E D_{\text {interstitial }}^{\text {DRF local }}=\frac{\mathscr{R}}{v} \times H E D_{\text {interstitial }}
\end{aligned}
$$

The pair of equations, Eq. (6), emphasises the dual nature of the DRF method for estimating the human equivalent dose, taking into account both the systemic $(\mathrm{mg} / \mathrm{kg}$ ) and local concentration $(\mathrm{mg} / \mathrm{ml})$ limits. It is unlikely that both equations will yield the same result; in which case, both should be taken into consideration when calculating the $M R S D$ value to use in first-in-man studies, as per Eq. (1).

\subsection{Measuring NOAELS}

We note in passing that whereas the determination of NOAEL values in animal models is a very well-known and understood procedure for intravenous agents, based on many years of experience in the pharmaceutical industry, the same cannot be said for interstitial administration of nanomedicines. To the knowledge of the authors, the concept of 'local toxicity' here is not something that has been either clearly defined or categorised for particulate nanomedicines. As such, there appears to be an area of fundamental toxicological research here that might warrant more academic scrutiny in the near future. In the meantime, studies of local toxicities and the estimation of animal-

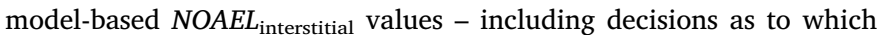
tests to perform, and what constitutes an observable effect - must be conducted on a case-by-case basis.

\section{DRF method for magnetic fluids}

To illustrate further the DRF method for estimating dosage limits for interstitial nanomedicine or agents on the basis of dispersion, retention, and formulation, we consider here the specific case of iron-oxide-based magnetic fluids. In doing so, we focus on the ultimate metric of interest, i.e. the prospective clinical therapeutic dose, $\mathscr{D}$. We note that this goes beyond the first-in-man clinical studies as discussed above, but it is meaningful in that it establishes a target for agent development, and can be appraised on the basis of the known characteristics of alreadyapproved agents.

\subsection{Clinical dose limits of existing agents}

Currently there are four clinically approved intravenous or interstitial iron-oxide-based magnetic fluids, the dose limits for which are given in Table 2. It should be noted that for the intravenous agents, Resovist $^{\circledR}$ and Feraheme ${ }^{\circledR}$, the dose limits quoted relate to the manufacturer's published instructions for use; but that for the interstitial agents, Sienna $+{ }^{\circledR}$ and Nanotherm ${ }^{\circledR}$, the dose limits have been derived from published data, using post-hoc assumed values for the dispersion factors of $v=2.4 \mathrm{ml}_{\text {tissue }} / \mathrm{ml}_{\text {fluid }}$ in both cases [7]. As such, the tabulated intravenous limits are expected to be more robust and reliable than the tabulated interstitial limits.

Assuming that each of these nanomedicines or agents have been optimised for its intended purpose, we surmise that the values listed in Table 2 are reasonable estimates of the maximum clinical dose limits,
Table 2

Published and derived dose limits for clinically-approved intravenous and in-

\begin{tabular}{|c|c|c|}
\hline Agent & Clinical Purpose & Injection Site and Dose Limit $\mathscr{D}_{0}$ \\
\hline Resovist $^{\circledast}$ & $\begin{array}{l}\text { MRI contrast agent for liver } \\
\text { lesions }\end{array}$ & Intravenous; up to $2.5 \mathrm{mg}_{\mathrm{Fe}} / \mathrm{kg}$ \\
\hline Feraheme $^{\circledast}$ & $\begin{array}{l}\text { Iron deficiency anaemia in } \\
\text { adults with chronic kidney } \\
\text { disease }\end{array}$ & $\begin{array}{l}\text { Intravenous; up to } 2.5 \mathrm{mg}_{\mathrm{Fe}} / \mathrm{kg} \\
\text { daily, up to } 8.5 \mathrm{mg}_{\mathrm{Fe}} / \mathrm{kg} \text { as a single } \\
\text { dose }\end{array}$ \\
\hline Sienna $+{ }^{\oplus}$ & $\begin{array}{l}\text { Sentinel lymph node } \\
\text { detection }\end{array}$ & $\begin{array}{l}\text { Interstitial (subcutaneous); up to } \\
12 \mathrm{mg}_{\mathrm{Fe}} / \mathrm{ml}_{\text {tissue }}\end{array}$ \\
\hline Nanotherm ${ }^{\oplus}$ & $\begin{array}{l}\text { Magnetic hyperthermia for } \\
\text { brain tumours }\end{array}$ & $\begin{array}{l}\text { Interstitial (intratumoural); up to } \\
40 \mathrm{mg}_{\mathrm{Fe}} / \mathrm{ml}_{\text {tissue }}\end{array}$ \\
\hline
\end{tabular}
terstitial magnetic fluids [7].

$\mathscr{D}_{0}$, for particulate iron oxides. It is notable that the limits vary depending on whether it is a single-dose or repeated injection; and that the interstitial limits are specific to the target tissues.

\subsection{Application to new product development}

As part of any product development programme, it is useful to have a target to work towards, and an early triage mechanism to allow for go/no-go decisions to be made in a timely and cost-effective manner. This is particularly so for nanomedicines and agents designed for clinical applications, where the evidentiary burden is high in order to obtain permission to conduct preclinical studies, and even more so to progress to first-in-man clinical studies.

With this in mind, we suggest a way to apply the DRF method to new product development, as follows. Let us suppose that our goal is to develop two iron-oxide-based agents, the hypothetical agents \#1 and \#2, for single-dose intratumoural and daily subcutaneous injection respectively. On the basis of the anticipated (or experimentally determined) DRF characteristics, we want to predict the dose limits that will apply to both the eventual clinical application, and to the earlier preclinical studies. We also want to know what could be the agent's maximum concentration.

Starting with agent \#1, let us suppose that we believe that we can produce an agent that has a moderate systemic tolerability, with an 'intravenous formulation factor' $\mathscr{F}$ i.v. $=0.40$, meaning that we expect that a dose at $40 \%$ of the $\mathscr{D}_{0}^{\text {i.v. }}$ established for Feraheme ${ }^{\circledR}$ for single-dose administration would be tolerated. Let us further suppose that we expect the 'retention factor' in the tumour to be good, at $\mathscr{R}=0.75$, meaning that we expect $75 \%$ of the injected dose to stay in the tumour, and $25 \%$ to transfer into the bloodstream.

For agent \#1 we can then estimate the maximum allowable dose, on the basis of the intravenous tolerability, from:

$\mathscr{D}_{\max }=\left(\mathscr{\mathscr { F }}^{\text {i.v. }} \times \mathscr{D}_{\mathrm{o}}^{\text {i.v. }}\right) /(1-\mathscr{R})$

which equals $13.6 \mathrm{mg}_{\mathrm{Fe}} / \mathrm{kg}$ (see Table 3). Thus for a $60 \mathrm{~kg}$ adult, we anticipate a maximum permissible dose of $816 \mathrm{mg}_{\mathrm{Fe}}$, of which $204 \mathrm{mg}_{\mathrm{Fe}}$ passes into the bloodstream.

To estimate the concentration limit for agent \#1 we need to consider the local tolerance in the tissue. Let us suppose that we expect to have excellent local tolerability, with an 'intratumoural formulation factor' $\mathscr{F}^{\text {i.t. }}=0.90$, so that a dose at $90 \%$ of the $\mathscr{D}_{0}^{\text {i.t. }}$ established for Nanotherm ${ }^{\circledR}$ would be tolerated. Let us further suppose that we expect the agent to disperse relatively easily in the tumour, with a dispersion factor of $v=3.0 \mathrm{ml}_{\text {tissue }} / \mathrm{ml}_{\text {fluid}}$.

The maximum allowable concentration of agent \#1, on the basis of the local tolerability, is then:

$c_{\max }=\left(\mathscr{F}\right.$ i.t. $\left.\times \mathscr{D}_{0}^{\text {i.t. }} \times v\right) / \mathscr{R}$

which equals $144 \mathrm{mg}_{\mathrm{Fe}} / \mathrm{ml}_{\text {fluid }}$ (see Table 3 ).

In this way, the DRF method has been used to predict a maximum permissible dose (that scales with patient mass) for agent \#1, and to set 
Table 3

DRF method calculations for two different hypothetical agents, as discussed in the text. (N.B. An Excel spreadsheet "DRF Calculator" is supplied as Supplementary Information and at www.resonantcircuits.com to facilitate these calculations.)

\begin{tabular}{|c|c|c|c|}
\hline Parameter & Agent \#1 & Agent \#2 & Comment \\
\hline \multicolumn{4}{|c|}{ Dispersion, Retention, Formulation: } \\
\hline$v$ & $3.0 \mathrm{ml}_{\text {tissue }} / \mathrm{ml}_{\text {fluid }}$ (in tumour) & $5.0 \mathrm{ml}_{\text {tissue }} / \mathrm{ml}_{\text {fluid }}$ (subcutaneous) & Dispersion factor \\
\hline $\mathscr{R}$ & 0.75 (in tumour) & 0.50 (subcutaneous) & Retention factor \\
\hline $\mathscr{F}$ i.v. & 0.40 (i.v.; relative to Feraheme ${ }^{\circledast}$ ) & 0.60 (i.v.; relative to Feraheme ${ }^{\circledast}$ ) & Formulation factors \\
\hline $\mathscr{F}$ i.t. $/ \mathscr{F}$ s.c. & 0.90 (local; relative to Nanotherm ${ }^{\circledast}$ ) & 0.90 (local; relative to Sienna ${ }^{\oplus}{ }^{\oplus}$ ) & \\
\hline \multicolumn{4}{|c|}{ Dose limit (clinical): } \\
\hline $\mathscr{D}_{0}^{\text {i.v. }}$ & $8.5 \mathrm{mg}_{\mathrm{Fe}} / \mathrm{kg}$ (single-dose) & $2.5 \mathrm{mg}_{\mathrm{Fe}} / \mathrm{kg}$ (daily dose) & as per Feraheme ${ }^{\circledast}$ \\
\hline \multirow[t]{2}{*}{$\mathscr{D}_{\max }$} & $13.6 \mathrm{mg}_{\mathrm{Fe}} / \mathrm{kg}$ & $3.0 \mathrm{mg}_{\mathrm{Fe}} / \mathrm{kg}$ & from Eq. (7) \\
\hline & $\therefore 816 \mathrm{mg}_{\mathrm{Fe}}$ & $\therefore 180 \mathrm{mg}_{\mathrm{Fe}}$ & for a $60 \mathrm{~kg}$ adult \\
\hline \multicolumn{4}{|c|}{ Dose limit (preclinical, murine): } \\
\hline \multirow[t]{2}{*}{$\mathscr{D}_{\max }$} & $168 \mathrm{mg}_{\mathrm{Fe}} / \mathrm{kg}$ & $37 \mathrm{mg}_{\mathrm{Fe}} / \mathrm{kg}$ & from Table 1 \\
\hline & $\therefore 3.35 \mathrm{mg}_{\mathrm{Fe}}$ & $\therefore 0.74 \mathrm{mg}_{\mathrm{Fe}}$ & for a $20 \mathrm{~g}$ mouse \\
\hline \multicolumn{4}{|c|}{ Concentration limit: } \\
\hline $\mathscr{D}_{0}^{\text {i.t. }} / \mathscr{D}_{0}^{\text {s.c. }}$ & $40 \mathrm{mg}_{\mathrm{Fe}} / \mathrm{ml}_{\text {tissue }}$ (as per Nanotherm ${ }^{\circledast}$ ) & $12 \mathrm{mg}_{\mathrm{Fe}} / \mathrm{ml}_{\text {tissue }}$ (as per Sienna $+{ }^{\oplus}$ ) & as indicated \\
\hline$c_{\max }$ & $144 \mathrm{mg}_{\mathrm{Fe}} / \mathrm{ml}_{\text {fluid }}$ & $108 \mathrm{mg}_{\mathrm{Fe}} / \mathrm{ml}_{\text {fluid }}$ & from Eq. (8) \\
\hline
\end{tabular}

a maximum permissible concentration for it. The method also establishes treatment limits. For example, for a $60 \mathrm{~kg}$ patient and the agent at "full strength", the maximum dose corresponds to $7.6 \mathrm{ml}_{\text {fluid }}$, and the largest treatable tumour volume is $22.7 \mathrm{ml}_{\text {tissue }}$. Such limits may be addressable during use (e.g. for smaller tumours, less agent may be injected; and for larger tumours, the agent may be suitably diluted prior to injection), but nevertheless they should be considered during the product development.

For comparison, data is included in Table 3 for agent \#2, for which we include a new set of assumed dispersion, retention, and formulation factors, and change both the administration site (from intratumoural to subcutaneous) and frequency (from single-dose to daily). Quite different conclusions are drawn compared to agent $\# 1$, with the dose limit for agent \#2 being only ca. $20 \%$ that of agent \#1. It is also notable that as the tissue compartment the agent is being injected into is unbounded (unlike a tumour), there is no local-administration limit on dose. Instead, the only guiding requirement is that the maximum permissible dose scales with the patient mass.

\subsection{Implications for preclinical testing}

One of the key objectives of the DRF approach is to relate the clinical product development to the design of preclinical models. Given that the preclinical work will undoubtedly precede the clinical, this may seem counterintuitive. However, it is essential to apply it this way, to thereby ensure that the preclinical data is both applicable to and informative for the subsequent human studies.

To illustrate this, the DRF-estimated dose limits for a murine model are listed in Table 3 for agents \#1 and \#2. In both cases the dose limit per unit mass are obtained by multiplying the human dose limit by the factor $K_{\mathrm{m}}{ }^{\text {mouse }} / K_{\mathrm{m}}$ human (adult) $=12.3$. The absolute limits for a $20 \mathrm{~g}$ mouse are estimated as ca. 3.35 and $0.74 \mathrm{mg}_{\mathrm{Fe}}$ respectively. For agent \#1 there is a further constraint on the tissue treatment volume, dependant on the concentration of the agent. At the $c_{\max }$ upper limit the maximum treatable tumour size is $70 \mu_{\text {tissue }}=70 \mathrm{~mm}^{3}$. As such it is clear that the DRF considerations may also inform decisions about the tumour models to employ in the preclinical model, and the timing of experiments in relation to the tumour growth.

\section{Conclusions}

In this contribution we have proposed a methodology based on the principles of dispersion, retention, and formulation, to enable predictive estimates to be made of dosage limits for interstitially administered nanomedicines or similar particulate-suspension agents. We have described how the method might be used to estimate the maximum recommended starting dose for first-in-man clinical studies, and we have illustrated how the method may be applied in the context of new product development, as a way of discerning the primary limiting characteristics of a given agent, and helping to inform the pathway to successful translational research. It is our hope that this is an approach that researchers in the field may find useful.

\section{Acknowledgements}

This work was supported in part by the European Commission Seventh Framework Programme through the Dartrix and NanoMag projects, under Grants 234870 and 604448, and by the European Commission Horizon 2020 Programme through the NoCanTher project, Grant 685795.

\section{Declaration of interest}

Both authors fulfil part-time paid executive (PS) or advisory (QAP) roles to a company (Resonant Circuits Limited) with commercial interests in magnetic hyperthermia. QAP also fulfils a part-time paid advisory role to a company (Endomagnetics Limited) with commercial interests in magnetic nanoparticles.

\section{Appendix A. Supplementary data}

Supplementary data to this article can be found online at https:// doi.org/10.1016/j.jmmm.2018.10.019.

\section{References}

[1] S. Kunjachan, J. Ehling, G. Storm, F. Kiessling, T. Lammers, Noninvasive imaging of nanomedicines and nanotheranostics: principles, progress, and prospects, Chem. Rev. 115 (2015) 10907-10937. 
[2] R. van der Meel, L.J. Vehmeijer, R.J. Kok, G. Storm, E.V. van Gaal, Ligand-targeted particulate nanomedicines undergoing clinical evaluation: current status, Intracellular Delivery III, Springer, Cham., 2016, pp. 163-200.

[3] J. Shi, P.W. Kantoff, R. Wooster, O.C. Farokhzad, Cancer nanomedicine: progress, challenges and opportunities, Nat. Rev. Cancer 17 (2017) 20-37.

[4] Y.S. Youn, Y.H. Bae, Perspectives on the past, present and future of cancer nanomedicine, Adv. Drug Delivery Rev. 130 (2018) 3-11.

[5] Guidance for industry: estimating the maximum safe starting dose in initial clinical trials for therapeutics in adult healthy volunteers. Published by: Center for Drug
Evaluation and Research, US Food and Drug Administration, USA, 2005.

[6] C.M. Dawidczyk, C. Kim, J.H. Park, L.M. Russell, K.H. Lee, M.G. Pomper,

P.C. Searson, State-of-the-art in design rules for drug delivery platforms: lessons

learned from FDA-approved nanomedicines, J. Contr. Release 187 (2014) 133-144.

[7] P. Southern, Q.A. Pankhurst, Commentary on the clinical and preclinical dosage

limits of interstitially administered magnetic fluids for therapeutic hyperthermia

based on current practice and efficacy models, Int. J. Hyperthermia 34 (2018) 671-686. 